\title{
The general demise of provincial psychiatric hospitals in Canada (until 2006)
}

\section{Introduction}

This article deals with the closure of Provincial Psychiatric Hospitals as we knew them in Canada up to 2006.

During the late 18th and early 19th century the mentally ill who were not considered dangerous or too much of a nuisance were left to wander at will in the forests, towns, and countryside. County jails as well as locked attics provided by frightened relatives were also common collecting places for the mentally ill.

Departments of health, welfare or corrections did not exist and were not anticipated in the early farming and pioneer environment. As industrialization proceeded and both the nuisance value of the mentally ill increased in town and country, ad hoc committees composed of politicians and occasional clergymen, doctors or judges were formed The penitentiaries and asylums came into being through this process. The social reform movement came about in the mid-19th century. In New Brunswick which has the distinction of having had the first provincial asylum, the 1836 Report of the Commissioners had as a central theme the moral treatment of the insane.

This treatment approach originating in the UK by the Tukes and Philippe Pine in France had a buoyant view of man and a sincere conviction that insanity could easily be cured. The consideration given to the location of a site, the floor plan, and the provision of amusements, occupation and religious worship was all intended to put these ideals into practice. One of the initial concerns in New Brunswick and similar to reports in other provinces was the avoidance of populated urban areas and the preference for a quiet, pastoral, semisecluded countryside for solely treatment concerns.

\section{a. The commissioners of the asylum were advised by a Mr. Lee that:}

It should not be too near a large city, or within half a mile of any street which is, or will likely become, a populous part of the Town. The location should be so elevated as to command a full view of the surrounding country, it should be in a region where the scenery is varied and delightful; a navigable river bearing on its basin the varieties of water craft, public roads thronged with the evidences if life and business. These objects will afford diversions and interest; excite conversation, and supply constant proofs that they are in a world of hope, and among beings who are engaged in the everyday business of life and everything about the establishment should give evidence of care and comfort.

The total population was never planned to exceed 200 patients. The original idea was one of a relatively small institution operated on a personal family group concept with the medical superintendent as the central figure. The social reform ideology of institutional care was steeped in the philosophy of linkages within the institution while the mentally ill were undergoing the treatment regimen known as moral therapy. Cure rates of $90-95 \%$ were often cited with the eventual goal of total integration into the community after the successful treatment had occurred. Ongoing community linkages were often thought to be both counter-therapeutic and a subversion of the required treatment.

\author{
Volume 5 Issue 3 - 2018
}

Sam Sussman
Department of Psychiatry, Western University, Canada

Correspondence: Sam Sussman, Department of Psychiatry, Western University, Sabbatical now in Vancouver, London, Ontario, Canada, Tel 604-901-4982,

Email samsussman@physicianscanada.net

Received: June 01, 2018 | Published: June 26, 2018

The notion of a retreat from society was firmly ensconced in the early treatment of the mentally ill. The treatment plan was and I quote:

"To divert the patient's mind from the subject or subjects of hallucinations, and to engage him in some mental exercises or amusements at stated times, and particularly to associate him with others, by whom his attention may be occupied, that he may have no time to indulge in, or brood over, his own illusions. Manual labour or exercise ...according to the rank and taste of the patient, and light cheerful conversation, with kindness and attention to all reasonable requests, and great but prudent firmness in resisting what is otherwise, is of the greatest consequence in treating the insane.

During the 1830 s and 1840 s the therapeutic ideal of providing humanitarian, non custodial institutional care promulgated by the early social reformers was supported by the general public. By the mid 1860s over 2200 patients were accommodated within 11 separate institutions in Ontario, Quebec, New Brunswick, Nova Scotia, P.E.I. and Newfoundland.

\section{b. The 1864 colonial office report observed that:}

"Insanity almost engrosses public attention and care in the North American colonies."

The reform of conditions for the mentally ill swept many frontier communities in a spectacular manner. The frustration of low recovery rates, an unanticipated demand for admissions and sharp increases in expenditure led to overcrowding and a paucity of human and fiscal resources.

Custodial care and the total demise of moral therapy by the very beginning of the 20th century were the resultant consequences by the year of Canada's Confederation in 1867. Within a few decades an almost full circle had occurred from social reform with its inherent social and community linkages to one of at best, benign neglect with features and phenomena of custodial care.

The Internal Linkages within the Victorian institution with the old mid-nineteenth century notion of the asylum as a parallel society died hard. The old asylums had kept their patients completely away from broader community, duplicating many community services, such as churches, shops, barbers and farms- the Victorian equivalent of a modern workplace. 
While health care systems were evolving after the Second World War, the mental hospital remained a total separate system with few bridges to the embryonic community health care system. Few community services were willing to accept discharged psychiatric patients. There were noteworthy and valiant attempts by provincially based hospitals to enter the new community care paradigm via linkages with general hospitals and community services. More often than not, the institution was unwelcome as were their patients.

Throughout Canada, mental health services were institutionally based by 1900 but substantial changes were in train. The beginning of the 20th century was characterized by four primary features:

a. The collapse of moral therapy.

b. The development of an organic, neuro-pathological orientation which offered psychiatrists an opportunity to move closer to mainstream medicine.

c. The beginning of a voluntary/volunteer movement.

\section{d. The impact of the World Wars.}

The effect of the two World Wars was to bring countless people into contact with psychiatric services who would not otherwise have been exposed to such services. Provisions of treatment and care with community and familial linkages were extended to groups of patients who were not, on the whole, as severely debilitated as the traditional "asylum patients." The long term effect was to introduce a range of new mental health services and corresponding models, e.g. care in general hospitals.

In 1918 the Canadian National Committee for Mental Hygiene $(\mathrm{CNCMH})$ a forerunner of the Canadian Mental Health Association (CMHA) was founded. From 1918 -1924 surveys of mental hospitals were commissioned to $\mathrm{CNCMH}$ by provincial governments to assess the conditions of mental hospitals in British Columbia, New Brunswick, Nova Scotia, Prince Edward Island and Saskatchewan.

\section{c. In P.E.I., the surveyors had this to say}

"It is difficult to believe an institution so conducted would be allowed to exist in a civilized country."

Their unsparing negative comments were echoed in its reports of conditions in the other provinces as well. Post World War I phenomena such as the introduction of intermediate hospitals (and as such a beginning attempt to break away from large mental hospitals in a few centres in Canada) hospital surveys and the introductions of child guidance and outpatient clinics of a stationary and travelling nature in the 1930s, 1940s and 1950s could be interpreted as beginning attempts of linkages with the community at large. The end of the Second World War did bring about an increased awareness of the mental health needs of the entire populace in Canada. Mental illness was at last considered to be a concern of all residents of the country and not solely a matter of "asylum."

In Canada there are examples of mental health networks that go back to the 1950s and 1960s. In Montreal in the late 1950s, there was a network of services and central co-ordination through the Department of Psychiatry at McGill University. The Province of Saskatchewan had eight regional centres with outreach teams in the 1960s based on a general hospital in each region with an array of psychiatric services. In Ontario, the McMaster model in Hamilton dates back to the late 1960s and is still functioning today. The model provides a comprehensive range of psychiatric services.
By April of 1972 all the provinces and the two territories of Canada adopted Medicare the universal health care plan of this country. Psychiatric patients and their treatment were covered by the various provincial government plans. Concurrent with the introduction of Medicare, the federal spending power provided grants for hospital construction. This created linkages to the community; in a substantive, substantial, concrete manner.

For the mentally disturbed outside of provincial psychiatric hospitals, the general hospital and as such psychiatric care in the community became viable alternatives to provincial institutionalization. Psychiatric units in general hospitals ware established throughout Canada and Dr. Henderson (formerly the Executive Director of the Government of Ontario's Mental Health Division) stated in Pioneers of Mental Health and Social Change that the grants for psychiatric beds were even higher than for acute medical treatment beds in general hospitals.

However, psychiatric units were not established in all instances in a harmonious way; in many general hospitals throughout Canada there was great reluctance to develop them. The legislation which permitted psychiatric units in Ontario did so under two conditions. The first was that the provisions for detention in the psychiatric unit of a general hospital would be identical to those of a provincial psychiatric hospital. The other requirement was the patients in a psychiatric unit would be under the care of psychiatrists. In many instances the latter condition was interpreted very broadly by hospital administrators to mean a medical ward exclusively for psychiatric patients without the necessary treatment infrastructure (e.g. psychiatrists, psychiatric nurses and the multidisciplinary team) for the treatment of mental illness.

The significance which Medicare had for the quality of care regarding provincial psychiatric institutions in Ontario (which was not atypical for the rest of Canada), was summed up by the following quote taken from the presenter's volume entitled Pioneers of Mental Health and Social Change:

\section{d. Dr. Henderson}

Some of the superintendents openly resented the development of service in general hospitals which took psychiatrists and other personnel, which they felt were better deployed in mental hospitals... the only way of upgrading the resources and facilities of provincial hospitals was to have something else out there for purposes of comparison and it helped.

The National Health Grants Program introduced in mid 20th century Canada recognized the fiscal inability of the provinces left to themselves to upgrade mental health facilities and resources. It provided funds for outpatient services in general hospitals as well as capital costs for psychiatric beds in new general hospital facilities. It discriminated between acute care beds and psychiatric beds in the amount of $\$ 500.00$ (Acute care beds were funded at $\$ 1000$ per bed and psychiatric beds were funded at $\$ 1500$ per bed).

At the end of World War II a large number of psychiatrists who had seen service were engaged in private practice. While there were very few psychiatrists employed in private practice prior to World War II, by 1950 it was estimated that there were at least 400 .

This growth in private psychiatry increased the acceptance of psychiatrists outside the provincial mental hospital setting and provided something of a base for the later developments in community 
psychiatry. Despite the fact that there was a growing acceptance of psychiatry throughout the land, there was still great reluctance to establish psychiatric units in general hospitals.

Meanwhile, the provincial mental hospitals had deteriorated. During the war years, the mobilization and deployment of physical and human resources directed towards the war effort had engendered this state of affairs. World War II once again demonstrated vividly the reality of psychiatric breakdown and the importance of physical, psychological and sociological techniques in treatment. Mobilization of medical and ancillary personnel to cope with the medical emergency in the armed forces created deprivation at home, little short of devastating. Mental hospitals in particular suffered; the effects were reflected in the static, if not deteriorating conditions of these services lasting into the late $1940 \mathrm{~s}$.

In a 1952 survey of seven provinces by the Scientific Planning Committee of the $\mathrm{CNCMH}$ it was discovered that in small towns and rural areas there were few if any general hospitals providing psychiatric services and there were only eleven general hospitals providing psychiatric services in larger centres of population. Despite established bed capacities, it was estimated that the provincial psychiatric hospitals were overpopulated by at least $70 \%$.

The bed capacity in mental hospitals in Canada went from approximately 46,000 to 65,000 from 1949 to 1959 and patients on the books went from 58,400 to 76,400 during this same time period. Moreover, by 1959 there were only thirty-two psychiatric units in general hospitals with a total inpatient population of 872 patients.

By 1970 there was a marked change throughout Canada with 86 general hospitals offering psychiatric services to approximately 3,000 patients. By 1990, 191 general hospitals had psychiatric units, a further indication of the reversal of the nature of psychiatric care provided in the past in Canada. There were many reasons for this reversal which had synergistic and interactional qualities. They are as follows:

a. The financial incentives provided by the federal government in the form of Medicare's universal hospital insurance and hospital construction grants.

b. The growing acceptance of psychiatry.

c. The willingness if the provincial governments, and the mental health professionals, to participate in federal endeavours to "mainstream" psychiatric care from the provincial mental hospitals to general hospitals.

All this did much to bring about the practice of psychiatry in general hospitals and contributed significantly to the philosophy and practice of community care.

This was aided and abetted by the community psychiatry movement, the advocacy of social reformers and volunteer associations as well as advances in psychopharmacology, especially the introduction of phenothiazines, anti-depressants and anti-anxiety medications in the $50 \mathrm{~s}$ and $60 \mathrm{~s}$. All of these forces had a synergistic, complementary and interactive effect upon each other. By 1970 there were 249 full-time mental health clinics which represented almost a $100 \%$ increase since the end of World War II.

\section{e. In 1964 the royal commission on health services recommended:}

That henceforth all the discriminations on the distinction between physical and mental illness in the organization and provision of services for the treatment and attitudes upon which these discriminations are based be disavowed for all time as unworthy and unscientific.

Patient populations in all psychiatric hospitals plummeted due to the increased numbers of patients in general hospitals, nursing homes and special care facilities throughout Canada. This dehospitalization and corresponding depopulation of provincial institutions was in consonance with the 1964 Royal Commission on Health Services which stated:

"We believe that provinces should move with all due speed to remove all patients receiving or capable of receiving active care from mental hospitals and transfer then to general hospitals."

By 1976 , there were 15,011 patients in provincial mental hospitals in Canada compared to 47,633 in 1960.

In the twenty first century in Canada the provincial psychiatric hospital is a relic of the past. In 2006 it was stated that:

a. Although the majority (86.8\%) of hospitalized mental health cases are treated in general hospitals, (2008-2009).

b. Psychiatric hospitals continue to account for more than half (50.6\%) of all hospital days related to a mental health diagnosis, reflecting the longer stays among patients in these specialized facilities. In comparison with published figures for average length of stay dating back to 1982-1983.

c. Both the averages for general and psychiatric hospitals represent historic lows for length of hospital stay in Canada. (Hospital Mental Health Services in Canada, 2005-2006- Canadian Institute for Health Information).

Despite this "progress ", homelessness, trans-institutionalization and an increase in mentally ill patients who find themselves in penal institutions are very much part of the overall mosaic of psychiatric services in Canada.

\section{Acknowledgements}

None.

\section{Conflict of interest}

The author declares there is no conflict of interest. 